\title{
The role of intravascular ultrasound in percutaneous coronary intervention of complex coronary lesions
}

\author{
Yuvaraj Malaiapan ${ }^{1,2}$, Michael Leung ${ }^{1,2}$, Anthony J. White ${ }^{1,2}$ \\ ${ }^{1}$ Monash Heart, Monash Medical Centre, Clayton, VIC, Australia; ${ }^{2}$ Department of Medicine, Monash University, Clayton, VIC, Australia \\ Contributions: (I) Conception and design: Y Malaiapan; (II) Administrative support: Y Malaiapan; (III) Provision of study materials or patients: Y \\ Malaiapan; (IV) Collection and assembly of data: Y Malaiapan; (V) Data analysis and interpretation: Y Malaiapan; (VI) Manuscript writing: All \\ authors; (VII) Final approval of manuscript: All authors. \\ Correspondence to: Dr. Yuvaraj Malaiapan. Monash Heart, Monash Medical Centre 246 Clayton Road, Clayton, VIC 3168, Australia. \\ Email: yuvimheart@gmail.com.
}

\begin{abstract}
Intravascular ultrasound (IVUS) is a catheter-based coronary imaging technique. It utilises the emission \& subsequent detection of reflected high frequency (30-60 MHz) sound waves to create high resolution, cross-sectional images of the coronary artery. IVUS has been the cornerstone of intracoronary imaging for more than two decades. When compared to the invasive coronary angiogram which studies only the silhouette of the contrast-filled artery lumen, IVUS also crucially images the vessel wall. Because of this capability, IVUS has greatly facilitated understanding of the coronary atherosclerosis process. Such insights from IVUS reveal how commonly and extensively plain angiography underestimates the true extent of coronary plaque, the characteristics of plaques prone to rupture and cause acute coronary syndromes (lipid rich, thin cap atheroma), and a realisation of the widespread occurrence of vessel remodelling in response to atherosclerosis. Similarly, IVUS has historically provided salutary mechanistic insights that have guided many of the incremental advances in the techniques of percutaneous coronary intervention (PCI). Examples include mechanisms of in-stent restenosis, and the importance of high-pressure post-dilatation of stents to ensure adequate stent apposition and thereby reduce the occurrence of stent thrombosis. IVUS also greatly facilitates the choice of correct diameter and length of stent to implant. Overall, a compelling body of evidence indicates that use of intravascular ultrasound in PCI helps to achieve optimal technical results and to mitigate the risk of adverse cardiac events. In this review, the role of intravascular ultrasound as an adjunct to PCI in complex coronary lesions is explored. The complex coronary situations discussed are the left main stem, ostial stenoses, bifurcation stenoses, thrombotic lesions, the chronically occluded coronary artery, and calcified coronary artery disease. By thorough review of the available evidence, we establish that the advantages of IVUS guidance are particularly evident in each of these complex CAD subsets. In particular, some consider the use of IVUS to be almost mandatory in left main PCI. A comparison with other intracoronary imaging techniques is also explored.
\end{abstract}

Keywords: Intravascular ultrasound (IVUS); complex coronary lesions; left main stem; ostial; bifurcation; chronic total occlusion and coronary intervention

Submitted Feb 11, 2020. Accepted for publication Aug 13, 2020.

doi: $10.21037 / \mathrm{cdt}-20-189$

View this article at: http://dx.doi.org/10.21037/cdt-20-189

\section{Introduction}

Coronary angiography reveals coronary arteries as a planar silhouette of their contrast filled lumens. However, it does not provide information regarding the coronary arterial wall, the site of coronary atherosclerosis. The assessment of coronary stenosis using coronary angiography is by measuring luminal constriction in relation to the adjacent "normal segment" as reference, resulting in the estimation 


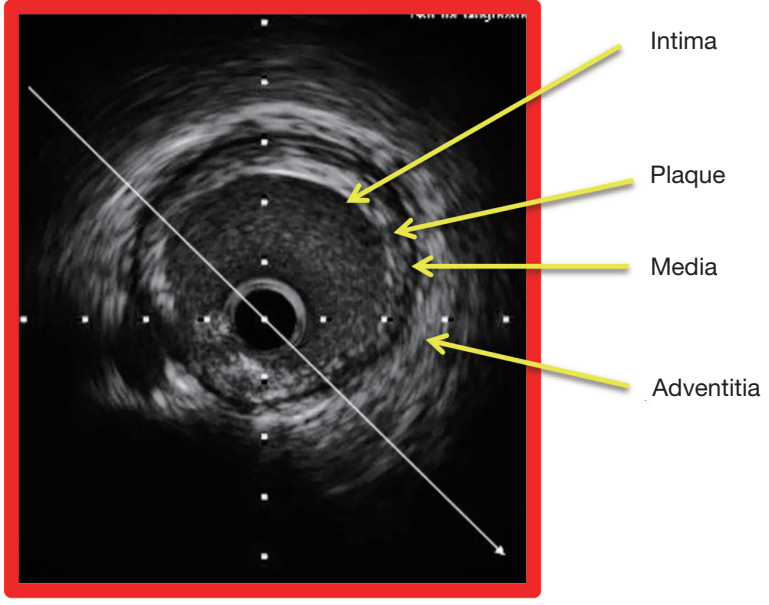

Figure 1 Typical intravascular ultrasound image depicting the trilaminar architecture of the coronary vasculature comprising intima, media and adventitia.

of the stenosis expressed as percent diameter stenosis. This way of assessing coronary stenosis does not convey the true extent of coronary atherosclerosis and is associated with significant inter-observer variability $(1,2)$.

Intracoronary imaging techniques such as intravascular ultrasound (IVUS) and optical coherence tomography (OCT) on the other hand, also image the arterial wall where the process of atherosclerosis actually occurs. Although these techniques provide valuable information during coronary imaging, they are used in only a small proportion of interventional cardiology procedures. The 2018 Society for Cardiovascular Angiography and Intervention Focused Update recommends the selective use of both IVUS and OCT especially in percutaneous coronary intervention (PCI) of complex coronary lesion subsets (3).

\section{IVUS-basic principles}

IVUS is a catheter-based imaging modality that provides high-resolution cross-sectional images of the coronary artery, enabling tomographic measurements of both the luminal and vessel areas. The sound waves thus generated by the transducers, travel through the different tissues components and are reflected according to the acoustic properties of the tissue (4). The axial resolution ranges between 100 to $200 \mu \mathrm{m}$ and the lateral resolution is approximately $250 \mu \mathrm{m}$ (5). There is also a newer iteration of IVUS called High Definition IVUS (HDi), which represents reinvention of the IVUS technology. It provides superior image quality because of proprietary technology of $60 \mathrm{MHz}$ transducer and state of the art image processing delivering axial resolution of $40 \mu \mathrm{m}$, minimised noise and greater depth of penetration.

IVUS provides an accurate way of assessing coronary atherosclerosis because of the excellent imaging quality and spatial resolution (6). In Figure 1, a typical image of trilaminar architecture of coronary artery obtained by IVUS is shown. Based on the ultrasound signal that is reflected from the coronary artery wall and its constituents, accurate representations of normal, fibrotic, calcific and vulnerable plaques (plaques with necrotic core) are reconfigured by the IVUS processing system. Tomographic and morphometric assessment of coronary vasculature and atherosclerosis thus obtained, has over the years, paved the way for consolidation of many of our fundamental understanding of coronary atherosclerosis, coronary intervention with balloon angioplasty and coronary stenting, in-stent restenosis (angiographic stenosis $>50 \%$ within the stent) and more recently, stent thrombosis.

IVUS also affords insights into the different types of plaque morphology, which is very useful in the planning of percutaneous coronary intervention procedure for instance, the necessity for the use of plaque modification device like rotational atherectomy in coronary lesions with calcified plaque (7). Based on the visual appearance of the atherosclerotic plaque, it is classified into soft plaque (echogenicity less than that of the adventitia), fibrotic plaque (echogenicity equivalent to that of the adventitia), calcified plaque (lesion echogenicity greater than that of the adventitia) and mixed plaque (containing elements of soft, fibrotic and calcified plaque) (Figure 2).

IVUS can also be used to identify vulnerable plaquedefined as eccentric plaque with a large lipid core, which may be prone to rupture (8-10). This concept has been confirmed by the adjunct use of angioscopy together with IVUS which showed that lipid rich plaque are indeed more prone to rupture (9). Additionally, information about the burden of atherosclerosis-plaque burden and plaque volume, area stenosis and lumen area which are measures of the compromise of coronary artery lumen can be accurately obtained using IVUS. The definition and derivation of commonly used morphometric IVUS measurements are shown in Table S1. Such in vivo lesion-specific information provides vital information in regards to managing coronary lesions appropriately-identifying lesions that can be treated with optimal medical therapy and lesions that can be treated by PCI (11). For instance, in the assessment 

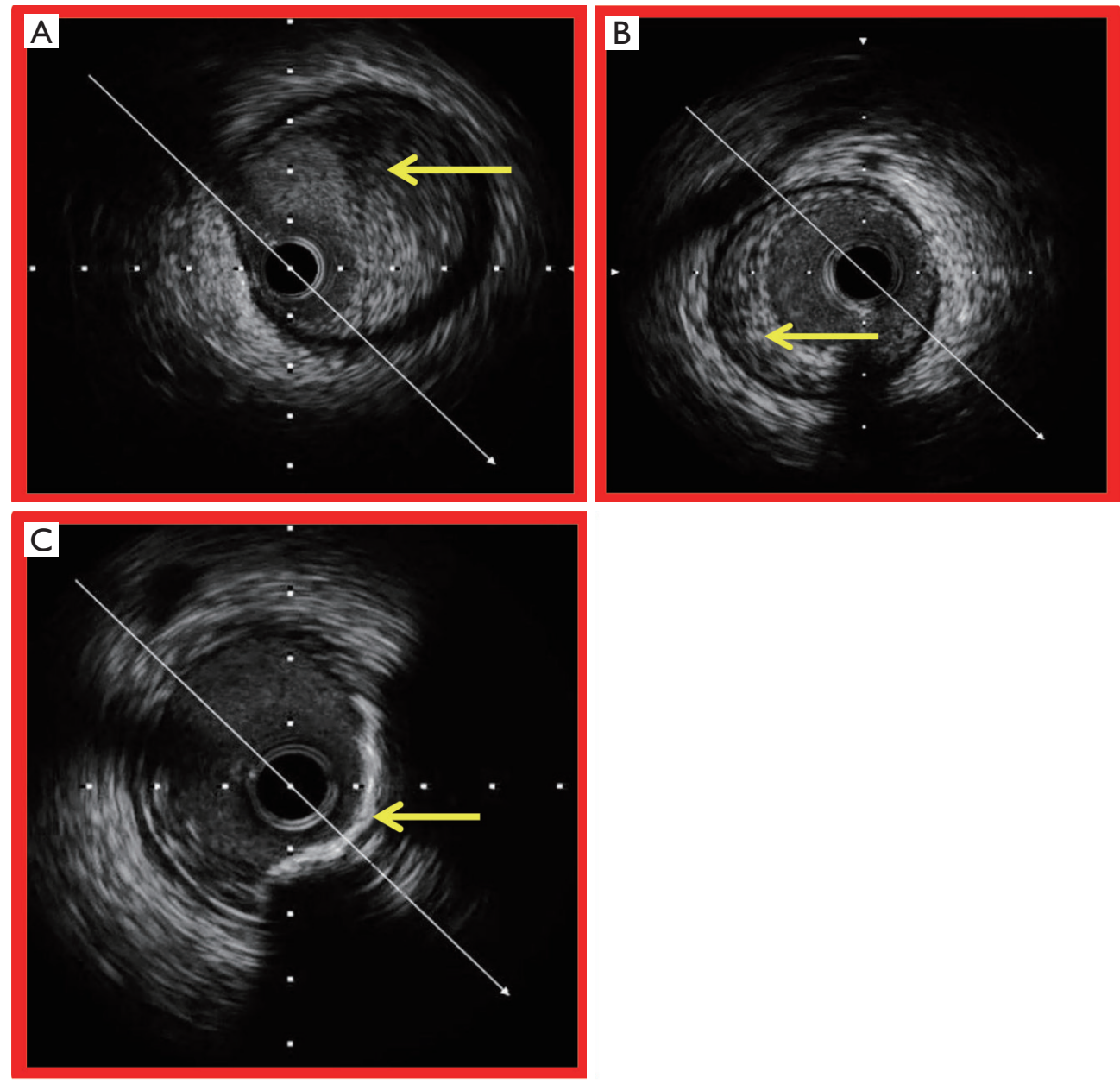

Figure 2 Different plaque morphologies. (A) Soft plaque with fibro fatty component and lipid core (yellow arrow). (B) Fibrofatty plaque (yellow arrow). (C) Calcified plaque (yellow arrow).

of intermediate left main stem (LMS) coronary lesions (50-70\% severity) (12), patients with LMS minimum lumen area of $>6 \mathrm{~mm}^{2}$ can have PCI safely deferred (6).

When used to guide PCI, IVUS accurately determines reference lumen dimensions and lesion length for appropriate sizing of stents. Other salutary insights that IVUS provides are information regarding predictors of adverse events following implantation of bare metal stents-smaller minimal stent area, stent under expansion, persistent edge dissections, incomplete stent apposition and incomplete lesion coverage (13). Historically, in stent restenosis in bare metal stent $(>50 \%$ luminal narrowing at follow up angiography) was a significant problem. IVUS helped to elucidate one of the main reason for thissmaller minimal stent area $(14,15)$. Other predictors of in stent restenosis in bare metal stents are smaller reference lumen diameter, longer stent length and smaller final lumen minimal lumen diameter (14). In the era of contemporary PCI using drug-eluting stents (DES), IVUS guidance was shown to reduce the rate of adverse outcomes by enabling physicians to achieve optimal stent result thus reducing in stent restenosis and stent thrombosis $(16,17)$. A propensity matched study comparing IVUS guidance and angiography guidance showed that IVUS guidance in the context of DES use was an independent predictor of freedom from cumulative stent thrombosis at 12 months (18). In a metaanalysis of eight randomised control trials of IVUS versus angiographic guided DES implantation, IVUS guidance was associated with reduction of major adverse cardiac events (MACE) by $41 \%$, mortality by $54 \%$, stent thrombosis by $51 \%$ and ischemia driven target lesion revascularization by $40 \%$ (19). In the epicardial coronary vessels, an optimal 
Table 1 Technical characteristics and differences of intra-coronary imaging modalities

\begin{tabular}{|c|c|c|c|c|}
\hline Characteristics & Grey-scale IVUS & FD-OCT & VH-IVUS & NIRS \\
\hline Axial resolution (um) & $100-200$ & $15-20$ & 200 & N/A \\
\hline Tissue penetration (mm) & $>5$ & $1-2.5$ & $>5$ & $1-2$ \\
\hline Pullback speed (mm/sec) & $0.5-1$ & $20-40$ & $0.5-1$ & 0.5 \\
\hline Image through blood & Yes & No & Yes & Yes \\
\hline
\end{tabular}

stent result by IVUS criteria is defined as complete apposition of stent struts to the intima, adequate stent expansion defined as minimum stent area of $>5.0 \mathrm{~mm}^{2}$ or $90 \%$ of distal reference lumen area and avoiding stent edge dissections $(6,20)$.

Understandably, there is a growing chorus of call for a more liberal use of IVUS guidance in PCI, especially in complex coronary lesions (21), defined as lesions located in the left main stem, ostial and bifurcation segments as well as lesions that are calcified, thrombus containing and chronic total occlusion (CTO) (22) where the benefits may be more pronounced $(23,24)$. However, this enthusiasm has to be counterbalanced with concerns that this benefit may be offset by increased cost of using IVUS in the cardiac catheterization laboratories (25). Reassuringly, the use of IVUS especially in PCI of complex coronary lesions has been shown to be cost effective by virtue of the reduction in MACE, especially the need for repeat revascularization $(22,26,27)$. For these reasons, IVUS has retained an ongoing and useful role in interventional cardiology for more than 25 years.

\section{IVUS compared to other intracoronary imaging modalities}

The contemporary usefulness of IVUS in complex coronary lesions may be better appreciated when it is compared to other intra coronary imaging tools like coronary angioscopy, near infrared spectroscopy-IVUS (NIRS-IVUS), virtual histology-IVUS (VH-IVUS) and OCT. The characteristics and differences of these intra-coronary imaging modalities are seen in Table 1.

Coronary angioscopy is a technique that employs direct visualisation of the coronary atherosclerotic plaque using an intra-coronary fiberscope. This offers excellent and direct view of coronary plaque and allows interrogation of the plaque for vulnerability, one of the key achievements of this intra coronary imaging modality (28). The other major use for coronary angioscopy is in the assessment of the completeness of drug eluting stent endothelialisation. This information is vital because inadequate endothelialisation of drug eluting stent may be associated with an increased risk for late stent thrombosis $(29,30)$.

NIRS-IVUS is a hybrid catheter system that yields both NIRS and high definition IVUS images, thus giving us vital insights into high-risk plaques and patients at elevated risk for future coronary events (31). The current NIRS system, using wavelength of $800-2,500 \mathrm{~nm}$, converts reflected signals to a spectrum that is then used to produce a computer-derived algorithm with lipid plaque represented on the yellow display range. This is useful in evaluating coronary atherosclerosis especially vulnerable plaque, the visualisation of which forms one of the limitations of IVUS. NIRS provides real time information about the lipid content of coronary plaques with $90 \%$ sensitivity and $93 \%$ specificity and has been validated in post mortem specimens (32). Combined with vascular structural information provided by IVUS, the NIRS-IVUS system holds significant promise in the identification of high risk lipid core lesions (33) and for the optimal stent coverage of such lesions.

In the last decade, spectral analysis of the radiofrequency backscatter signals known as VH-IVUS, has given us information about the plaque morphology-fibrous, fibrofatty, dense calcium and necrotic core (34). VH-IVUS has been used to show an association between vulnerable plaque (large lipid core and thin cap fibro-atheroma) and adverse long-term events in patients with non-culprit plaque (35).

Frequency domain OCT (FD-OCT) on the other hand uses light waves instead of sound waves. OCT provides high-resolution intra-coronary images based on nearinfrared interferometry. Near infra red light is emitted at approximately $1,300 \mathrm{~nm}$ wavelength and images are then 


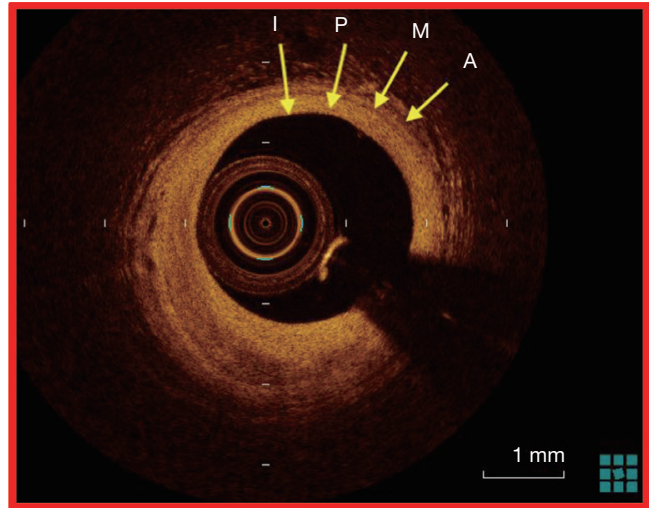

Figure 3 Typical OCT image. I: intima, P: plaque, M: media and A: adventitia.

configured by detection of backscattered light. FD-OCT requires clearance of blood prior to imaging (because red blood cells scatter infra red light) and offers superior axial and lateral resolution of 15 and $20-40 \mu \mathrm{m}$ respectively. Consequently, the enhanced spatial resolution of FD-OCT provides a much better visualization and appreciation of intracoronary pathological features that cannot be matched by IVUS (36) (Figure 3). There are several limitations associated with FD-OCT. Firstly, in patients with aortoostial lesions, because of the difficulty in intubating the coronary artery with a guide catheter, optimal blood clearance is not easily achieved resulting in poor image quality. Secondly, the penetration depth of FD-OCT is restricted to $1-3 \mathrm{~mm}$, thus larger, aneurysmal and positive remodelled coronary arteries cannot be assessed accurately. Thirdly, as radio opaque iodinated contrast is the medium that is used to clear the coronary artery prior to imaging, the reality of increased use of contrast and the subsequent risk of contrast induced kidney injury remains a possibility particularly in those with chronic kidney disease.

IVUS when compared to coronary angioscopy, NIRSIVUS, VH-IVUS and OCT, provides insights not only in the understanding of coronary atherosclerosis but also in the optimal way it can be treated with PCI. In this review, we will specifically look at the usefulness of IVUS in PCI of complex coronary lesions.

\section{IVUS in PCI of left main stem lesions}

Traditionally, left main stem (LMS) PCI has been one of the most challenging frontiers in interventional cardiology because angiographic assessment of intermediate coronary lesions in left main stem may be fraught with inconsistencies with regards to lesion severity assessment (37). In the Coronary Artery Surgery Study (CASS), interpretation of LMS findings in coronary angiography was the least reproducible (38) and assessment of LMS lesion severity was noted to be associated with significant inter observer variability (39). These inconsistencies may also be due to the fact that coronary angiography frequently underestimates the true severity of coronary lesions (40) because: (I) diffuse disease of LMS renders assessment of diameter stenosis by coronary angiography difficult due to the lack of a reference segment, (II) a short LMS also leads to poor visualisation of a reference segment leading to an over or under estimation of the LMS calibre, (III) ostial LMS lesions preclude intubation and optimal opacification of the LMS due to contrast streaming, thus limiting accurate assessment of its dimensions and (IV) the presence of overlapping daughter vessels may prevent satisfactory visualization of the distal LMS and ostial LAD/ LCx (41). It is also noteworthy that a high percentage of patients with angiographically normal LMS may indeed have angiographically silent disease-atherosclerotic disease detected by IVUS but not by coronary angiography; and even when there is angiographically detectable disease, correlation between IVUS and angiography is poor in terms of stenosis severity assessment (42). IVUS thus provides insights into true morphologic severity of LMS lesions that may aid in choosing the best management option in these patients (43) and when PCI is the chosen treatment option, IVUS helps the treating physician to strategize appropriately by choosing the right devices in order to achieve optimal PCI result (44) (Figure 4).

Although, coronary artery bypass surgery has traditionally been the preferred option of revascularization, there is growing body of supporting evidence for the safety and efficacy of PCI in LMS both acutely as well as in the mid to long term (45-48). The use of IVUS for PCI with DES in LMS lesions is also known to be associated with better overall clinical outcome. Conversely, the non-use of IVUS in LMS PCI has been identified as an independent predictor of major adverse events including cardiac death, myocardial infarction (MI), need for target lesion revascularization (TLR) and stent thrombosis (ST) (49,50), leading many in the field to consider IVUS almost mandatory when performing PCI to the left main stem. In a large Korean (MAIN COMPARE) registry that studied the benefit of routine of IVUS guidance in LMS PCI (49), Park et al. compared the three-year outcome of 2 propensity-matched 

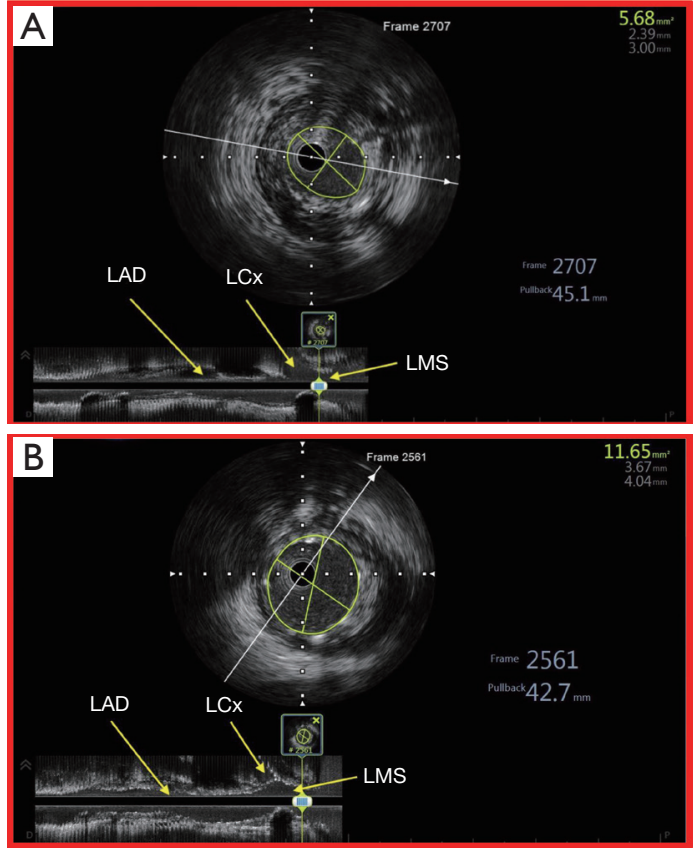

Figure 4 IVUS guided left main stem PCI. (A) Left main stem: pre PCI—significant stenosis (minimum luminal area $5.68 \mathrm{~mm}^{2}$ ). (B) Left main stem: post PCI-optimal stent result (minimum stent area $11.65 \mathrm{~mm}^{2}$ ).

cohorts of IVUS versus angiography guided LMS PCI. In 145 matched pairs of patients who received drug-eluting stents, the three-year incidence of mortality was lower in the IVUS guidance group ( $4.7 \%$ versus $16 \%, \log$-rank $\mathrm{P}=0.05$; hazard ratio, 0.39 ; $95 \%$ CI: 0.15 to 1.02 ; Cox model $\mathrm{P}=0.055)$. When the outcome was adjusted using propensity score, the risk of adverse outcome at three years were reduced by $60 \%$ in the IVUS guided LMS PCI group (49). Such a benefit may be explained by the fact that the use of IVUS leads to better stent expansion and consequently improved stent apposition.

In the landmark EXCEL trial, where patients with significant LMS coronary artery stenosis (angiographic stenosis $\geq 70 \%$ or $\geq 50 \%$ to $<70 \%$ with non invasive evidence of left main ischemia/IVUS MLA $\leq 6 \mathrm{~mm}^{2} /$ fractional flow reserve $\leq 0.8$ ) with low to intermediate SYNTAX score were randomised to either coronary artery bypass surgery or PCI with second generation Everolimus eluting stent, PCI was considered non-inferior to CABG with respect to the composite of death, stroke or myocardial infarction at 3 years. It's noteworthy that $77 \%$ of patients who underwent PCI in the EXCEL trial had IVUS guidance.
The utility of IVUS in LMS PCI can also be better appreciated by looking at the segments within the left main stem where PCI may be associated with increased adverse outcomes. Of the 3 LMS segments (ostial, body and distal), PCI of the distal segment lesions is associated with worse outcomes (51). This is due to the composition and distribution of the atherosclerotic plaque in this segment, which are usually more diffuse and mixed (with significant fibro calcific composition). This can result in suboptimal stenting result and potentially increase the rate of adverse cardiac events. The benefit of using IVUS especially in the distal LMS was seen in the IVUS-TRONCO-ICP study, which was a pooled analysis of 4 large Spanish PCI registries (50). IVUS guidance in distal LMS PCI was associated with improved survival free from major adverse cardiac events (death, MI and TLR). The use of IVUS emerged as an independent predictor for fewer adverse events in the overall population and especially in the subgroup of patients with distal LMS disease, even when 2 stents were used. It therefore makes biological sense to use IVUS in distal LMS PCI where there is a greater necessity to obtain the best possible stent result, simply because of the amount of myocardium subtended. The assessment of distal LMS using IVUS is preferably done with pullback from both LAD and LCx because this provides excellent morphologic information about the LMS atherosclerotic disease process (52) and its extent into LAD and LCx. This has significant impact on the decision-making during the PCI procedure-in adopting a single versus two stent strategy (MLA at the LCx ostium $>4.0 \mathrm{~mm}^{2}$ and a plaque burden $<50 \%$ is rarely associated with an Fractional Flow Reserve (FFR) $<0.8$ after single stent crossover) (53). IVUS also provides critical information in PCI of ostial LMS lesions because optimal ostial stent coverage can be confirmed and further optimization of stent expansion may be undertaken where necessary (Figure 5).

The criteria used to determine optimal stent result in the LMS are-optimal stent apposition, expansion and minimum stent area that predicts angiographic restenosis- $5.0 \mathrm{~mm}^{2}$ for the LCx ostium, $6.3 \mathrm{~mm}^{2}$ for the LAD ostium, $7.2 \mathrm{~mm}^{2}$ for the polygon of confluence and $8.2 \mathrm{~mm}^{2}$ for the proximal LMS $(54,55)$. It is not surprising that the Society of Cardiovascular Angiography and Interventions position statement in 2018 considered IVUS as an important procedural adjunct both in pre and post procedural evaluation in LMS PCI (56). 

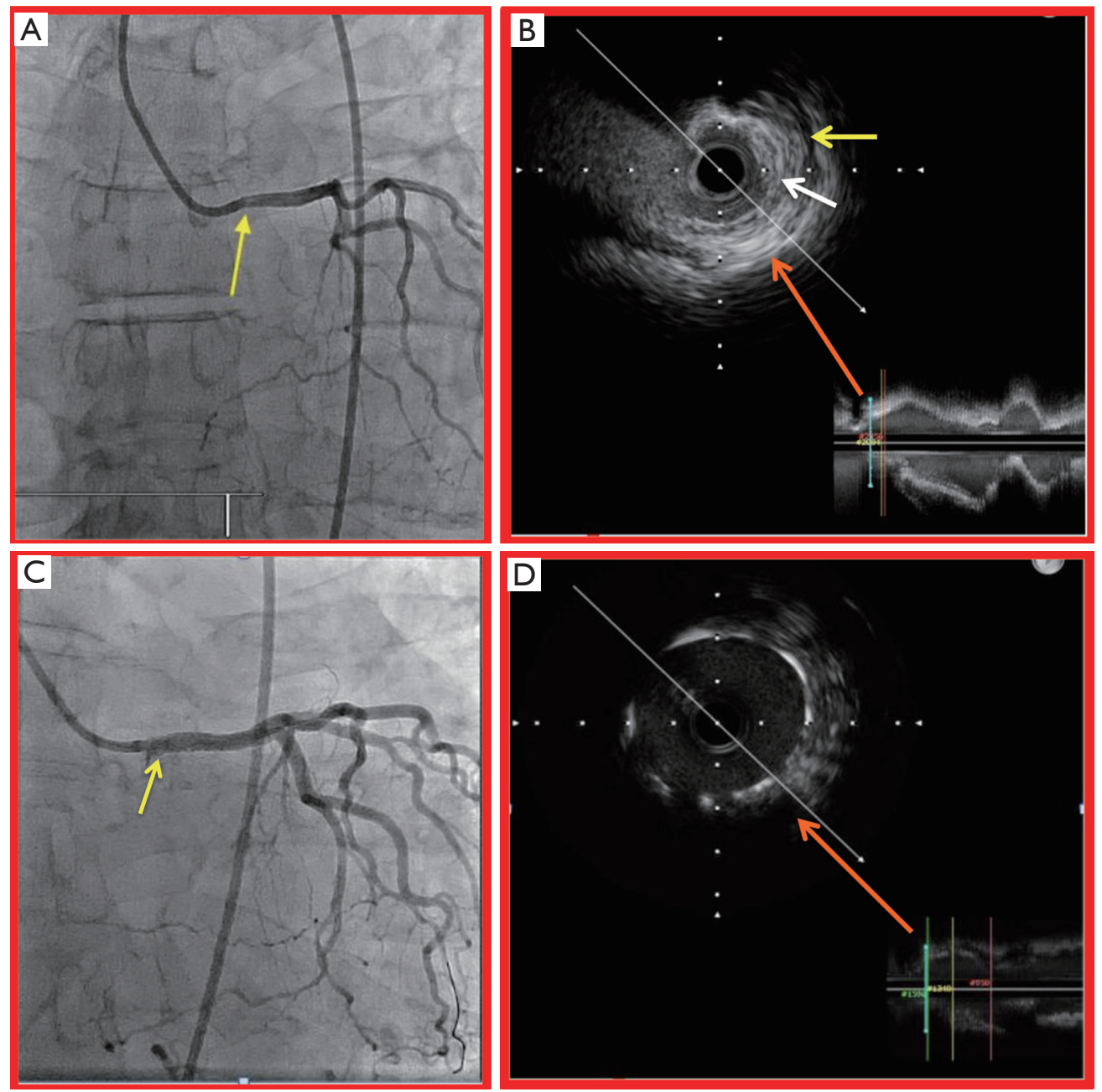

Figure 5 Ostial LMS lesion in a 70 years old man with angina CCS 2 and strongly positive stress echo for multi-vessel ischemia. (A) Coronary angiogram: dampening of pressure upon engagement of LMS with 50\% ostial LMS stenosis (yellow arrow), which persisted with intracoronary Glyceryl Trinitrate. RCA, chronically occluded at the proximal segment. SYNTAX score $=18$. (B) IVUS of LMS: significant and eccentric fibrotic plaque (media indicated by yellow arrow and plaque indicated by white arrow). LMS MLA $5.9 \mathrm{~mm}^{2}$. Cross section at the ostium of LMS indicated by orange arrow. (C) After stenting of LMS ostium (yellow arrow). (D) IVUS pullback following stenting of LMS ostium. Minimum stent area 9.2 $\mathrm{mm}^{2}$ with optimal ostial LMS stent coverage. Cross section at the ostium of LMS indicated by orange arrow.

\section{IVUS in PCI of ostial coronary artery lesions}

PCI of coronary ostial lesions is technically challenging and may be associated with higher rates of adverse cardiac events compared with PCI of non-ostial coronary lesions $(57,58)$. This is most likely due to the type of plaque found at these sites (fibrotic, calcific or fibro-calcific) that results in suboptimal stenting result consequent to inadequate stent expansion (59). Additionally, PCI of ostial lesions may be associated with geographical miss defined as inadvertent stent deployment that misses the desired target area (60), which in this case is the ostium. This is attributed to the inability to obtain co-axial alignment of the guide catheter prior to stent deployment, with the resultant movement of the stent from the desired anatomical location due to "melon-seeding." This can result in higher rates of restenosis and target lesion revascularization $(60,61)$. Inadvertent movement of the stent proximally, resulting in protrusion into the aorta, may impede intubation of the coronary artery during subsequent coronary angiography whereas melon seeding of the stent distally requires additional stenting to cover the ostium due to geographical miss. 

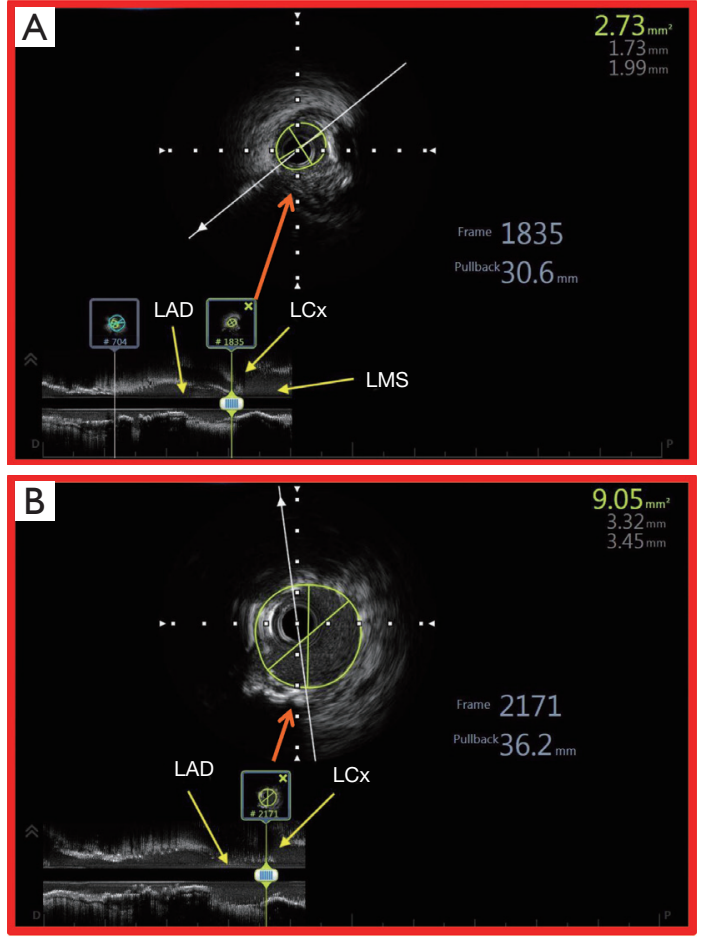

Figure 6 IVUS Guided Ostial LAD PCI. (A) Pre PCI IVUS pullback across LAD ostium (fibro-calcific plaque with minimum luminal area $2.73 \mathrm{~mm}^{2}$ ). Cross section at the ostium indicated by orange arrow. (B) Post PCI IVUS pullback reveals optimal stent expansion (minimum stent area $9.05 \mathrm{~mm}^{2}$ ). Cross section at the ostium indicated by orange arrow.

The incidence of geographical miss can be as high as $10 \%$, when IVUS is used after stenting to assess stent result (62). Coronary ostial lesions are located at either the aorto-ostial or at the major coronary ostial segments (e.g., LAD/LCx).

\section{Aorto-ostial lesions}

Aorto-ostial compared to LAD/LCx ostial lesions poses greater challenge because aorto-ostial lesions are more resistant to expansion. This is due to increased elastic tissue and muscular content (59). This may result in stent underexpansion, one of the predictors of stent thrombosis (63). It is interesting that ostial right coronary artery (RCA) lesions are associated with greater restenosis compared to ostial left main stem lesions (62) though the reason for this observation is unclear. The use of IVUS to guide PCI of aorto-ostial lesions has the potential to help operators to prepare the lesion well before stenting, choose stent of appropriate dimension and ensure optimal ostial coverage and stent result.

When compared with OCT, IVUS is more advantageous in the aorto-ostial coronary lesions because of the fact that such lesions would prevent optimal coronary guide catheter intubation, an important prerequisite for OCT where blood clearance with contrast is mandatory for optimal visualization of vascular structures. In addition, the presence of diffuse atherosclerosis involving the entire LMS precludes optimal visualization of the LMS ostium. In such situations, IVUS is the better modality as the guide catheter may be withdrawn from the LMS in order to visualise the entire length of the LMS (64).

\section{LAD/LCx ostial lesions}

In LAD/LCx ostial coronary lesions, IVUS reveals diffuse distribution of plaque, extending from the proximal LAD/ LCx and into the LMS (65). Thus, the use of IVUS may help in choosing longer stents to ensure optimal plaque coverage especially in the distal LMS if the distal LMS plaque burden is $\geq 50 \%$ (66). Further optimization of the stent result in the distal LMS can be achieved confidently using IVUS. When IVUS is used to guide PCI in $\mathrm{LAD} / \mathrm{LCx}$ ostial coronary lesions, there is a significant reduction in long term adverse cardiac outcomes (62). The use of IVUS in these lesions helps physicians to strategize appropriately by choosing devices like rotational atherectomy or cutting balloon to remodel the plaque so as to enable delivery of stent and achieving optimal stent expansion and apposition eventually. IVUS thus aids in the selection of stent that is of appropriate length and diameter, suited to the true dimension of the coronary artery and extent of atherosclerotic plaque (Figure 6). Finally, IVUS also helps in identifying suboptimal stent expansion that can then be dealt with acutely by more aggressive post dilatation (23).

In summary, in PCI of both aorto-ostial and LAD/LCx ostial coronary lesions, IVUS has a significant role to play and its use results in optimal acute results and reduced adverse events in the long term (67).

\section{IVUS in PCI of coronary bifurcation lesions}

Coronary bifurcation lesion PCI remains a uniquely challenging anatomic subset associated with increased need for repeat revascularization. This is because of various factors including variability in plaque burden, plaque morphology, angle of bifurcation and vessel diameter that 
makes optimal result elusive especially in true bifurcation lesions (68). The use of drug eluting stents for coronary bifurcation lesions has however reduced the need for repeat revascularization (68). The variability in decision making in regards to salvaging side branch has also been largely resolved by adopting a single stent procedure as a default strategy (69-71). IVUS helps in this regard by firstly providing pre intervention information that helps in the decision-making whether the side branch requires salvage. A pre-intervention MLA of $\geq 2.4 \mathrm{~mm}^{2}$ in the side branch could predict non ischemic post intervention FFR $\geq 0.8$ (predictive value 98\%), thus helping operators to avoid side branch PCI. If the pre-intervention side branch MLA $\leq 2.4 \mathrm{~mm}^{2}$, then clinical judgment have to employed to determine if the side branch required salvaging as a post intervention FFR $\geq 0.8$ could not be accurately determined (predictive value $40 \%$ ) (6).

Given the anatomic complexity of coronary bifurcation lesions, the variability of plaque morphology and the flow dynamics, it makes sense that IVUS should be used to firstly strategize the PCI procedure appropriately and secondly to achieve optimal stent result especially in light of the everpresent spectre of stent thrombosis, albeit at a reduced rate in the era of newer generation DES (17,72-74). Though the use of IVUS is not recommended in all coronary bifurcation PCI, there are certain bifurcation subsets in the epicardial coronary vessels where IVUS may be useful. These are proximal LAD/diagonal and thrombotic bifurcation lesions, especially in acute coronary syndrome. IVUS in the proximal LAD/Diagonal affords vital information regarding the diffuse nature of atherosclerotic plaque across the Diagonal branch which may impact the success of the PCI procedure because of the risk of plaque shifting into the side branch following stent implantation in the main vessel (75). In thrombotic bifurcation lesion where the use of DES has been noted to be associated with a higher risk for late stent thrombosis (74), the use of IVUS helps in achieving optimal stent result, mitigating the risk of future MACE and possibly even death.

\section{IVUS in PCI of LAD/diagonal bifurcation lesion}

In LAD/Diagonal bifurcation lesions, it appears a very reasonable strategy to use IVUS to ensure optimal stent result. In a large Korean bifurcation registry of 1,668 patients, a propensity-matched cohort of 487 patients was compared for IVUS versus angiography guidance in coronary bifurcation PCI. Target lesions were in the
LAD in $83 \%$ of patients in both groups. The incidence of death or myocardial infarction was significantly lower in the IVUS-guided group compared to the angiographyguided group $(3.8 \%$ vs. $7.8 \%, \log$ rank test $\mathrm{P}=0.03$, hazard ratio 0.44 , 95\% CI: 0.12-0.96, Cox model $\mathrm{P}=0.04)(76)$. It would therefore appear that IVUS has a role to play in optimization of stent result in this challenging anatomic subset. It is imperative to aim for a final minimum stent area of at least $5 \mathrm{~mm}^{2}$ in both the main vessel and side branch to mitigate the risk of MACE (Figure 7).

\section{IVUS in PCI of thrombotic bifurcation lesions}

One of the disadvantages of IVUS is that it is not an ideal intra coronary imaging modality for visualisation of thrombus because there are no pathognomonic features for the accurate diagnosis of thrombus. In lesions with large atherothrombotic burden, the final stent result may be suboptimal because of the difficulty in assessing true coronary artery dimensions predisposing to early stent thrombosis (77). These lessons may be even more important in coronary bifurcation lesions where 2 stents have to be deployed i.e., bifurcation lesions where both the main vessel and the ostium of a sizeable branch vessel $(>2.5 \mathrm{~mm}$ in diameter) have severe thrombus containing lesions. Despite its limitation, IVUS can still aid in the determination of true vessel dimension as well as the burden of atherothrombotic disease, thus enabling the operator to choose appropriately sized stents and anticipate slow flow (78). In stent thrombosis involving bifurcation lesions, IVUS offers insights that help to elucidate the causes for the stent failure-neo-intimal hyperplasia, neo atherosclerosis, under sized stents, under expansion of stent, mal-apposition of stent struts (lack of contact of stent struts with intimal surface) and stent edge restenosis (79).

In coronary bifurcation PCI, especially involving proximal LAD/diagonal branch and thrombotic lesions, IVUS has a vital role in helping to achieve excellent acute procedural result and mitigation of MACE events in the long term.

\section{IVUS in PCI of chronic total occlusions}

Chronic total occlusion (CTO) of coronary arteries is encountered in about $10-15 \%$ of cases (80). There is compelling evidence to show that successful recanalization of CTO's is associated with significant reduction in angina and corresponding improvement in quality of life $(12,48)$. 

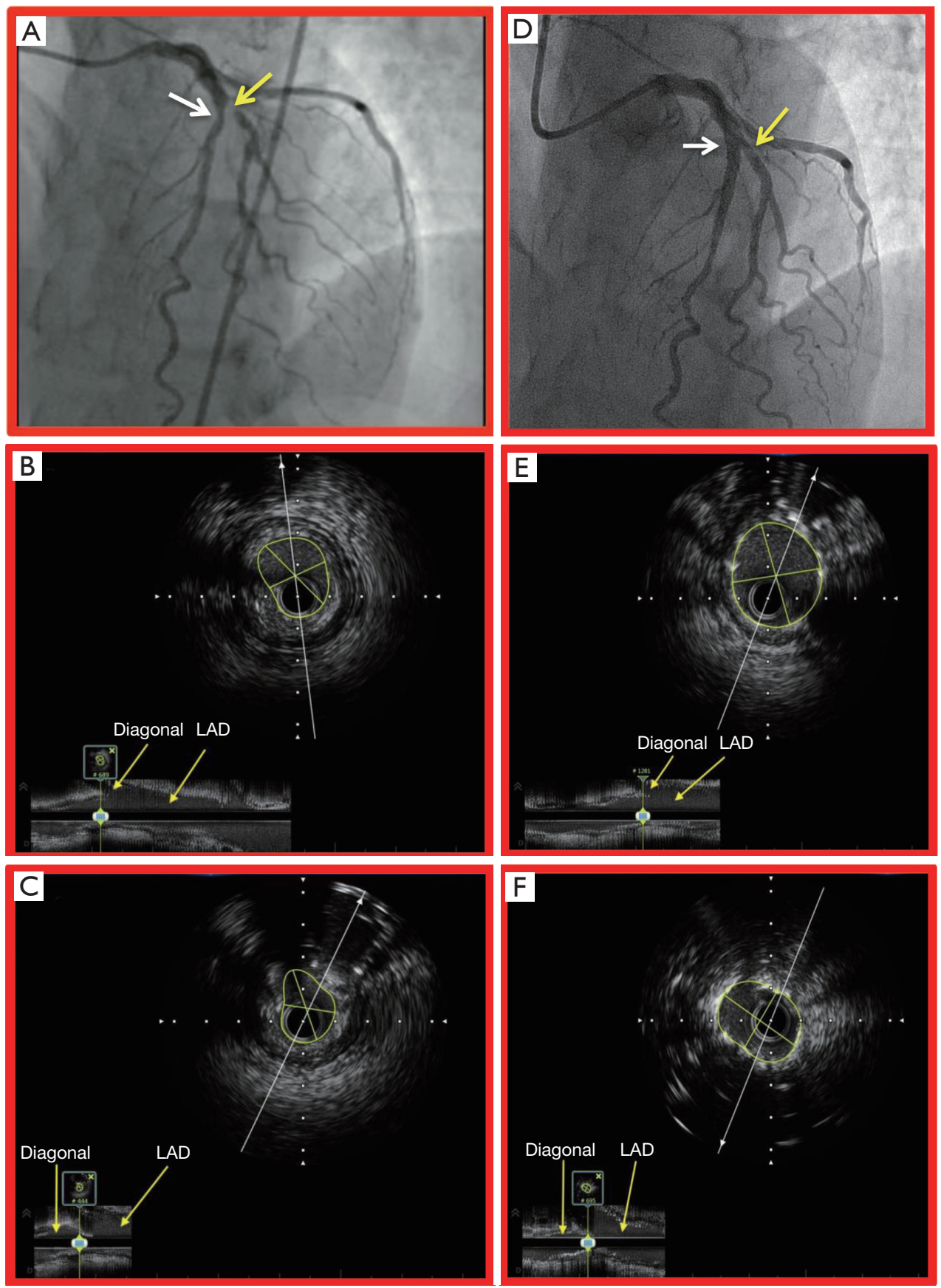

Figure 7 IVUS guided bifurcation PCI using 2 stents in a 57 years old man with angina CCS 3 and strongly positive exercise stress test. (A) Pre PCI coronary angiogram. Sub-totally occluded moderate caliber diagonal branch (yellow arrow) at the ostium and mild 40-50\% stenosis of the LAD adjacent to the diagonal branch (white arrow). (B) Pre PCI IVUS run of LAD (minimum luminal area 4.2 mm²). (C) IVUS run of Diagonal branch following pre-dilatation (minimum luminal area $2.8 \mathrm{~mm}^{2}$ ). (D) Coronary angiogram after stenting of both the LAD (white arrow) and Diagonal branch (yellow arrow). (E) Post PCI IVUS run of LAD (optimal stent result with minimum stent area $7.97 \mathrm{~mm}{ }^{2}$ ). (F) Post PCI IVUS run of Diagonal branch (optimal stent result with minimum stent area $5.11 \mathrm{~mm}^{2}$ ). 


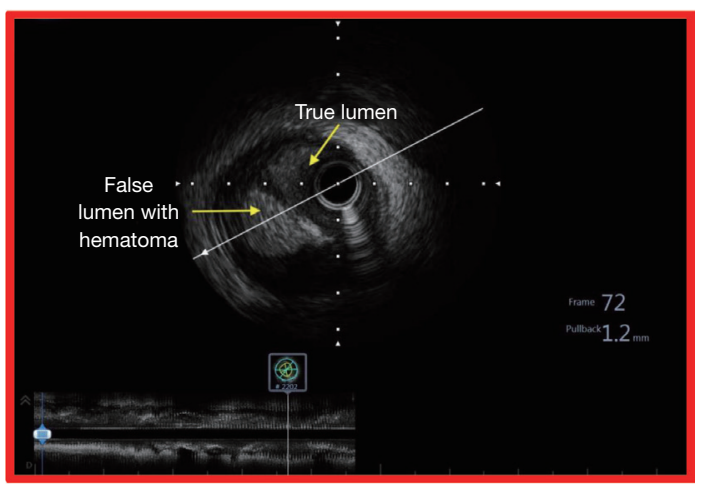

Figure 8 IVUS pullback of RCA CTO lesion following successful wire crossing using ante-grade wire escalation strategy. False lumen was noted with hematoma, highlighting the sub-intimal passage of the first coronary of guide wire, which then led to successful crossing with a second guide wire.

Traditionally CTO PCI was associated with only a modest success rate. However, in the last decade, revascularization of CTO has gained significant momentum with the (I) advancement in dedicated CTO coronary guidewires and (II) the development of hybrid ante-grade and retrograde approach for recanalization of CTO. These have significantly increased the success rates in CTO PCI (81). Successful CTO-PCI is known to be associated with improvement in angina status, exercise tolerance, survival and reduction in major adverse cardiac events (MACE) (82-84). However, there are still specific anatomic subsets within the CTO realm that pose a significant challenge.

\section{IVUS in antegrade CTO PCI}

In ambiguous, blunt or even absent proximal cap of the CTO (with an adjacent side branch), the use of IVUS enables the operator to precisely identify the true lumen. In this procedure, IVUS pullback is performed from the side branch and during the course of the pullback, the true origin of the CTO may be appreciated. Having identified the origin of the CTO, the proximal cap of the CTO can then be punctured using a stiff coronary guidewire, using IVUS guidance in real time (85). This has the potential to increase the success rate of such challenging CTO subset significantly (86). IVUS also helps in confirming luminal position of the wire along the course of the CTO. In antegrade CTO PCI, IVUS detected the sub-intimal position of the wire in more than half of all successful CTO PCI cases (Figure 8). In the majority of such cases $(86.7 \%)$, dissection and re-entry approach was adopted (87). Additionally, IVUS also gives the operator the true dimension of the CTO vessel, plaque distribution and burden thus facilitating not only the selection of appropriately sized stent but also in achieving optimal stent result (6).

\section{IVUS in retrograde CTO $\mathrm{PCI}$}

In retrograde approach for CTO recanalization, the use of IVUS helps in understanding the location of both the antegrade and retrograde wires (88). IVUS is used at the stage of the procedure when both the ante-grade and the retrograde wires are in the CTO segment. After balloon dilatation of the CTO segment on the antegrade wire, the IVUS catheter is first passed onto the antegrade wire and IVUS images are obtained. This crucial information helps the operator to facilitate the passage of the retrograde wire from false into the true lumen primarily by determination of the position of the antegrade wire $(48,89)$. In a series where IVUS was used to guide retrograde CTO PCI in previously failed CTO procedures, when CART (controlled antegrade and retrograde sub-intimal tracking) or reverse CART was performed, IVUS revealed the sub-intimal position of the antegrade wires more often $(59.5 \%)$ whereas the retrograde wires were located in the intimal space $(61.7 \%)$. This insight was critical in helping the operators to steer the retrograde wire into the true lumen ensuring high procedural success rate (90).

\section{Other uses for IVUS in CTO PCI}

A CTO length of more than $20 \mathrm{~mm}$ is known to be associated with lower procedural success rates (91). The passage of wires in long CTO's are challenging especially in tortuous anatomy, as there is significant risk of sub intimal passage of the wire. IVUS assists the operator to ensure the luminal position of the coronary guide wire. In the event the first wire finds a sub intimal passage, IVUS can be used for parallel wire technique, where a second coronary guide wire may be directed into the true lumen using the first wire as an anatomic marker. A novel IVUS based $3 \mathrm{D}$ wiring of CTO lesions where the wire tip detection is significantly improved, has the promise of even greater success especially in this CTO subset (92).

It is clear then that IVUS plays a significant role in CTO recanalization, both in ante-grade and retrograde 

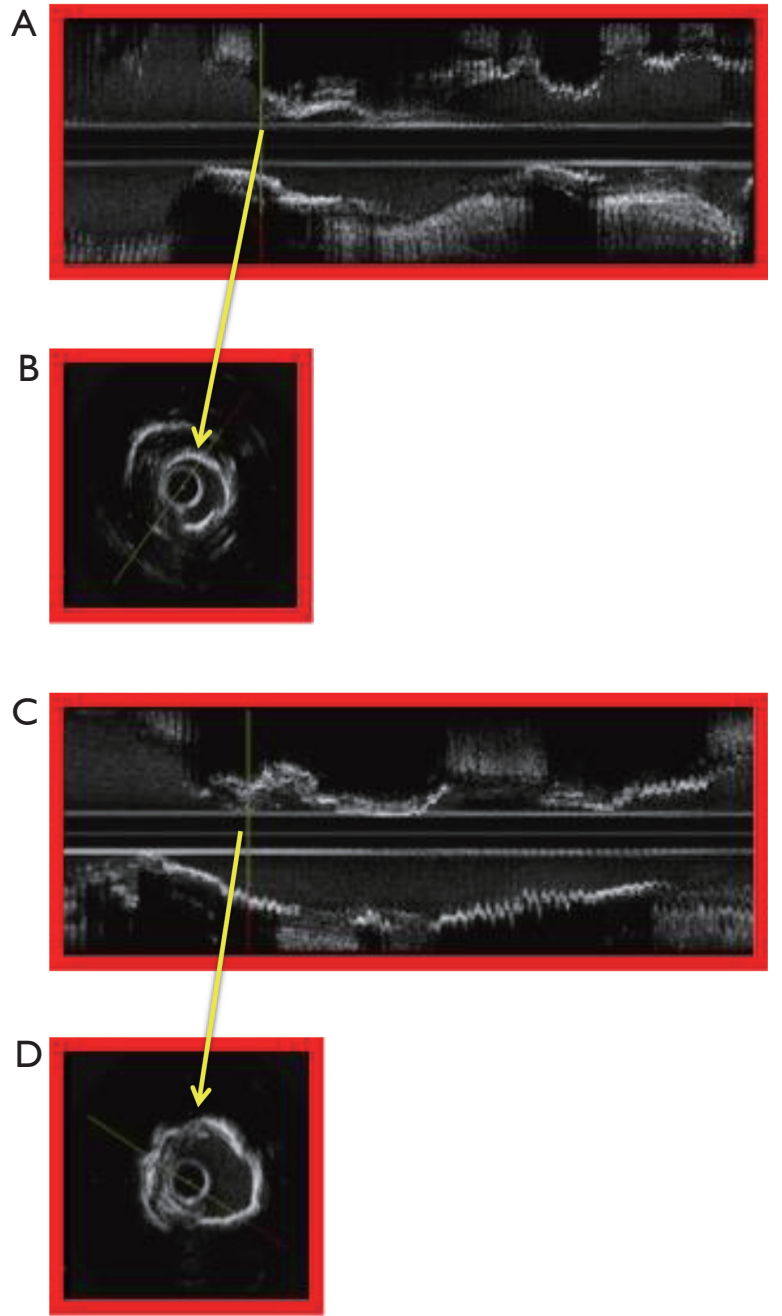

Figure 9 Pre and post rotational atherectomy of proximal LAD. (A) Longitudinal IVUS pullback across proximal LAD, pre rotational atherectomy. (B) Cross sectional (pre rotational atherectomy) image of severe proximal LAD stenosis with $360^{\circ}$ arc of superficial calcification (yellow line). (C) Longitudinal IVUS pullback across proximal LAD post rotational atherectomy. (D) Cross sectional (post rotational atherectomy) image of proximal LAD stenosis (yellow line) revealing a larger lumen.

approaches. In CTO, the lesion subsets where IVUS is most useful are: (I) ambiguous, blunt or absent proximal cap in the ante-grade approach (85), (II) for the accomplishment of CART or reverse CART in the retrograde approach (90) and (III) for the determination of luminal passage of coronary guide wire in long CTO's. The use of IVUS to guide CTO PCI may be associated with significant reduction in major adverse cardiac event rate $(93,94)$ including stent thrombosis $(33,92,93)$.

\section{IVUS in calcified coronary lesions}

Coronary artery calcification (CAC) is significantly underestimated by coronary angiography whereas IVUS accurately reveals not only the presence of calcification but also its distribution (superficial/deep) and its severity (based on the arc of calcification) $(95,96)$. CAC remains one of the most important predictors of adverse outcome after PCI (22). In the era of balloon angioplasty, presence of severe calcification was a predictor of significant dissection after balloon dilatation (97) and in the era of contemporary PCI using drug eluting stents, presence of calcification may be associated with late stent thrombosis (98).

IVUS enables accurate assessment of the burden of CAC and to answer the all-important question whether the calcified plaque requires modification using rotational atherectomy prior to stent implantation (Figure 9). An arc of calcium that is more than $180^{\circ}$ is associated with suboptimal stent symmetry (99) and an arc of calcification more than $270^{\circ}$ is associated with increased need for the use rotational atherectomy and greater likelihood of stent mal-apposition (100) following stent implantation, which may be associated with increased risk for late stent thrombosis.

\section{IVUS guided rotational atherectomy for calcified coronary lesions}

There is a potential role for IVUS in angiographically calcified coronary lesions because when calcification is angiographically visible and at least of moderate severity, IVUS reveals that the arc of calcium is likely to be large and superficial (101). When used in such lesions, IVUS helps to identify those that truly require plaque remodelling with RA i.e., lesions with superficial calcification with arc $>180^{\circ}$, considered to be severely calcified lesions by IVUS criteria (101). This has the potential for improved outcomes. Importantly, the risk of stent thrombosis in sub optimally expanded stents may be mitigated.

Rotational atherectomy (RA) is a technique that enables plaque modification by using the preferential ablation principle in fibrotic or calcified coronary lesions (102). In the randomised ROTAXUS trial (103), 240 patients were randomized either to RA PCI or standard PCI. Though there was increased acute luminal gain favouring the RA 
PCI $\operatorname{arm}(1.56 \pm 0.43$ vs. $1.44+0.49 \mathrm{~mm}, \mathrm{P}=0.01)$, late lumen loss at 9 months was higher in the RA arm $(0.44 \pm 0.58 \mathrm{vs}$. $0.31 \pm 0.52, \mathrm{P}=0.04)$ compared to standard PCI arm. Instent binary restenosis $(11.4 \%$ vs. $10.6 \%, \mathrm{P}=0.71)$, target lesion revascularization $(11.7 \%$ vs. $12.5 \%, \mathrm{P}=0.84)$, definite stent thrombosis $(0.8 \%$ vs. $0 \%, \mathrm{P}=1.0)$, and major adverse cardiac events $(24.2 \%$ vs. $28.3 \%, \mathrm{P}=0.46)$ were similar in both groups. At 9 months, there was no significant reduction in MACE in RA PCI arm compared to standard PCI. Based on this study, routine RA appears to be not as useful in PCI of moderate to severely calcified coronary lesions. Yet, in this study, despite the fact that close to $50 \%$ of lesion were considered severely calcified by angiographic criteria, IVUS use was not mandated. In the prospective, multicentre, observational MACE trial (84), designed to look at the impact of calcification on procedural and long term outcomes, stratified by calcification severity by angiographic core lab, about $95 \%$ of patients had rotational atherectomy for calcified lesions that were considered both moderate and severe. IVUS guidance for RA was not mandated. Both lesion and procedural success were lower in severely calcified lesions- $83.3 \%$ versus $94.7 \%$ of none or mildly calcified lesions, $\mathrm{P}=0.006$ and $86.8 \%$ versus $95 \%$ of moderately calcified lesions, $\mathrm{P}=0.03$ respectively. The 1 -year MACE (cardiac death, myocardial infarction and target vessel revascularization) rates were higher in the severely calcified lesions $(24.4 \%)$ compared to moderate $(8.7 \%)$ and none/mildly calcified lesions $(4.7 \%)(\mathrm{P}<0.001)$. The use of IVUS in both these studies may have helped in achieving greater plaque remodelling and consequently larger final stent dimension. This could have translated to a greater reduction in MACE.

In this complex lesion subset, IVUS offers valuable information other than just the burden of calcification. IVUS parameters such as reference lumen dimension, minimal luminal diameter, cross sectional area of the lumen at the stenotic site and importantly, post stent dimension including stent symmetry and expansion help in strategizing appropriately during the procedure. Reference maximum luminal diameter aids in choosing the correct stent size; mean (stenosis) luminal diameter may aid in the selection of the appropriate burr size and post stent IVUS information aids the operator in choosing appropriate balloon size for post dilatation in order to achieve optimal stent result. The use of a single burr, based on the mean luminal diameter, has cost saving potential. We know that moderate to severely calcified lesions exist in a milieu of diffuse disease. IVUS therefore gives salutary insight into the length of the lesion that needs to be stented, avoiding geographical miss.

In moderate to severely calcified coronary lesions, IVUS guidance helps in adopting appropriate PCI strategy especially in regards to plaque modification with RA. Conversely, the use of IVUS also helps to identify lesions where the procedure may be completed using conventional PCI techniques, thus saving cost and avoiding small (1.3\%) but potentially dangerous complications associated with procedures like RA (56). Further adequately powered study using IVUS, is needed to identify the subset within the cohort of patients with moderate to severely calcified lesions who may benefit from RA PCI.

\section{Conclusions}

IVUS remains a niche technology in interventional cardiology. The 2018 Society for Cardiovascular Angiography and Intervention guideline considers IVUS to be definitely beneficial in achieving optimal stent result and probably beneficial in guiding PCI in complex lesion subsets (3).

IVUS has proven to be a valuable tool in cardiac catheterization laboratories in the era of contemporary PCI practice especially in complex coronary lesion subsets like LMS, ostial, bifurcation, CTO and calcified coronary lesions. In these lesion subsets, IVUS provides significant and salutary insights that not only has the potential to alter the intra procedural course favourably and reduce major adverse cardiac events in the long term (104) but also translates to cost saving because of the potential for rational use of devices in the catheterization laboratories and reducing the need for repeat revascularization procedures $(26,27)$.

\section{Acknowledgments}

Funding: None.

\section{Footnote}

Provenance and Peer Review: This article was commissioned by the Guest Editor (Dennis Wong) for the series "Intracoronary Imaging" published in Cardiovascular Diagnosis and Therapy. The article was sent for external peer review organized by the Guest Editor and the editorial office.

Conflicts of Interest: The authors have completed the 
ICMJE uniform disclosure form (available at http://dx.doi. org/10.21037/cdt-20-189). The series "Intracoronary Imaging" was commissioned by the editorial office without any funding or sponsorship. The authors have no other conflicts of interest to declare.

Ethical Statement: The authors are accountable for all aspects of the work in ensuring that questions related to the accuracy or integrity of any part of the work are appropriately investigated and resolved.

Open Access Statement: This is an Open Access article distributed in accordance with the Creative Commons Attribution-NonCommercial-NoDerivs 4.0 International License (CC BY-NC-ND 4.0), which permits the noncommercial replication and distribution of the article with the strict proviso that no changes or edits are made and the original work is properly cited (including links to both the formal publication through the relevant DOI and the license). See: https://creativecommons.org/licenses/by-nc-nd/4.0/.

\section{References}

1. Topol EJ, Nissen SE. Our preoccupation with coronary luminology. The dissociation between clinical and angiographic findings in ischemic heart disease. Circulation 1995;92:2333-42.

2. Zir LM, Miller SW, Dinsmore RE, et al. Interobserver variability in coronary angiography. Circulation 1976;53:627-32.

3. Lotfi A, Davies JE, Fearon WF, et al. Focused update of expert consensus statement: Use of invasive assessments of coronary physiology and structure: A position statement of the society of cardiac angiography and interventions. Catheter Cardiovasc Interv 2018;92:336-47.

4. Kornowski R, Mintz GS, Kent KM, et al. Increased restenosis in diabetes mellitus after coronary interventions is due to exaggerated intimal hyperplasia. A serial intravascular ultrasound study. Circulation 1997;95:1366-9.

5. Lotfi A, Jeremias A, Fearon WF, et al. Expert consensus statement on the use of fractional flow reserve, intravascular ultrasound, and optical coherence tomography: a consensus statement of the society of cardiovascular angiography and interventions. Catheter Cardiovasc Interv 2014;83:509-18.

6. McDaniel MC, Eshtehardi P, Sawaya FJ, et al. Contemporary clinical applications of coronary intravascular ultrasound. JACC Cardiovasc Interv 2011;4:1155-67.

7. Smith SC, Jr., Feldman TE, Hirshfeld JW, Jr., et al. ACC/ AHA/SCAI 2005 guideline update for percutaneous coronary intervention: a report of the American College of Cardiology/American Heart Association Task Force on Practice Guidelines (ACC/AHA/SCAI Writing Committee to Update 2001 Guidelines for Percutaneous Coronary Intervention). Circulation 2006;113:e166-286.

8. Yamagishi M, Terashima M, Awano K, et al. Morphology of vulnerable coronary plaque: insights from follow-up of patients examined by intravascular ultrasound before an acute coronary syndrome. J Am Coll Cardiol 2000;35:106-11.

9. Takano M, Mizuno K, Okamatsu K, et al. Mechanical and structural characteristics of vulnerable plaques: analysis by coronary angioscopy and intravascular ultrasound. J Am Coll Cardiol 2001;38:99-104.

10. Garcia-Garcia HM, Costa MA, Serruys PW. Imaging of coronary atherosclerosis: intravascular ultrasound. Eur Heart J 2010;31:2456-69.

11. Zheng M, Choi SY, Tahk SJ, et al. The relationship between volumetric plaque components and classical cardiovascular risk factors and the metabolic syndrome a 3-vessel coronary artery virtual histology-intravascular ultrasound analysis. JACC Cardiovasc Interv 2011;4:503-10.

12. Ramadan R, Boden WE, Kinlay S. Management of Left Main Coronary Artery Disease. J Am Heart Assoc 2018;7.

13. Uren NG, Schwarzacher SP, Metz JA, et al. Predictors and outcomes of stent thrombosis: an intravascular ultrasound registry. Eur Heart J 2002;23:124-32.

14. Kasaoka S, Tobis JM, Akiyama T, et al. Angiographic and intravascular ultrasound predictors of in-stent restenosis. J Am Coll Cardiol 1998;32:1630-5.

15. Hoffmann R, Mintz GS, Mehran R, et al. Intravascular ultrasound predictors of angiographic restenosis in lesions treated with Palmaz-Schatz stents. J Am Coll Cardiol 1998;31:43-9.

16. Jang JS, Song YJ, Kang W, et al. Intravascular ultrasoundguided implantation of drug-eluting stents to improve outcome: a meta-analysis. JACC Cardiovasc Interv 2014;7:233-43.

17. Moses JW, Dangas G, Mehran R, et al. Drug-eluting stents in the real world: how intravascular ultrasound can improve clinical outcome. Am J Cardiol 2008;102:24J-8J.

18. Roy P, Steinberg DH, Sushinsky SJ, et al. The potential clinical utility of intravascular ultrasound guidance in 
patients undergoing percutaneous coronary intervention with drug-eluting stents. Eur Heart J 2008;29:1851-7.

19. Elgendy IY, Mahmoud AN, Elgendy AY, et al. Outcomes With Intravascular Ultrasound-Guided Stent Implantation: A Meta-Analysis of Randomized Trials in the Era of DrugEluting Stents. Circ Cardiovasc Interv 2016;9:e003700.

20. Raber L, Mintz GS, Koskinas KC, et al. Clinical use of intracoronary imaging. Part 1: guidance and optimization of coronary interventions. An expert consensus document of the European Association of Percutaneous Cardiovascular Interventions. Eur Heart J 2018;39:3281-300.

21. Maluenda G, Pichard AD, Waksman R. Is there still a role for intravascular ultrasound in the current practice era? EuroIntervention 2010;6 Suppl G:G139-44.

22. Wilensky RL, Selzer F, Johnston J, et al. Relation of percutaneous coronary intervention of complex lesions to clinical outcomes (from the NHLBI Dynamic Registry). Am J Cardiol 2002;90:216-21.

23. Witzenbichler B, Maehara A, Weisz G, et al. Relationship between intravascular ultrasound guidance and clinical outcomes after drug-eluting stents: the assessment of dual antiplatelet therapy with drug-eluting stents (ADAPTDES) study. Circulation 2014;129:463-70.

24. Joner M, Finn AV, Farb A, et al. Pathology of drug-eluting stents in humans: delayed healing and late thrombotic risk. J Am Coll Cardiol 2006;48:193-202.

25. Gaster AL, Slothuus U, Larsen J, et al. Cost-effectiveness analysis of intravascular ultrasound guided percutaneous coronary intervention versus conventional percutaneous coronary intervention. Scand Cardiovasc J 2001;35:80-5.

26. Gaster AL, Slothuus Skjoldborg U, Larsen J, et al. Continued improvement of clinical outcome and cost effectiveness following intravascular ultrasound guided PCI: insights from a prospective, randomised study. Heart 2003;89:1043-9.

27. Alberti A, Giudice P, Gelera A, et al. Understanding the economic impact of intravascular ultrasound (IVUS). Eur J Health Econ 2016;17:185-93.

28. Uchida Y, Uchida Y, Kawai S, et al. Detection of vulnerable coronary plaques by color fluorescent angioscopy. JACC Cardiovasc Imaging 2010;3:398-408.

29. Uchida Y. Recent advances in coronary angioscopy. J Cardiol 2011;57:18-30.

30. Takano M, Ohba T, Inami S, et al. Angioscopic differences in neointimal coverage and in persistence of thrombus between sirolimus-eluting stents and bare metal stents after a 6-month implantation. Eur Heart J
2006;27:2189-95.

31. Waksman R, Di Mario C, Torguson R, et al. Identification of patients and plaques vulnerable to future coronary events with near-infrared spectroscopy intravascular ultrasound imaging: a prospective, cohort study. Lancet 2019;394:1629-37.

32. Moreno PR, Lodder RA, Purushothaman KR, et al. Detection of lipid pool, thin fibrous cap, and inflammatory cells in human aortic atherosclerotic plaques by nearinfrared spectroscopy. Circulation 2002;105:923-7.

33. Virmani R, Burke AP, Farb A, et al. Pathology of the vulnerable plaque. J Am Coll Cardiol 2006;47:C13-8.

34. Nair A, Margolis MP, Kuban BD, et al. Automated coronary plaque characterisation with intravascular ultrasound backscatter: ex vivo validation.

EuroIntervention 2007;3:113-20.

35. Stone GW, Maehara A, Lansky AJ, et al. A prospective natural-history study of coronary atherosclerosis. N Engl J Med 2011;364:226-35.

36. McCabe JM, Croce KJ. Optical coherence tomography. Circulation 2012;126:2140-3.

37. Skyrme-Jones RA, Mottram P, Meredith IT. The use of intravascular ultrasound imaging for the assessment of left main stem coronary disease before bypass surgery. Int J Clin Pract 2001;55:650-1.

38. Fisher LD, Judkins MP, Lesperance J, et al. Reproducibility of coronary arteriographic reading in the coronary artery surgery study (CASS). Cathet Cardiovasc Diagn 1982;8:565-75.

39. Pandian NG, Hsu TL. Intravascular ultrasound and intracardiac echocardiography: concepts for the future. Am J Cardiol 1992;69:6H-17H.

40. White CJ, Ramee SR, Collins TJ, et al. Ambiguous coronary angiography: clinical utility of intravascular ultrasound. Cathet Cardiovasc Diagn 1992;26:200-3.

41. Mottram PM, Meredith IT. Intravascular ultrasound assessment of ambiguous coronary lesions. Heart Lung Circ 2001;10:58-62.

42. Zientek DM, Rodriguez ER, Liebson PR, et al. Validation of computerized three-dimensional reconstruction of intravascular ultrasound: measurements of absolute luminal diameter and cross-sectional area in ex vivo human coronary arteries. J Invasive Cardiol 1992;4:179-87.

43. Wolfhard U, Gorge G, Konorza T, et al. Intravascular ultrasound (IVUS) examination reverses therapeutic decision from percutaneous intervention to a surgical approach in patients with alterations of the left main stem. Thorac Cardiovasc Surg 1998;46:281-4. 
44. Das P, Meredith I. Role of intravascular ultrasound in unprotected left main percutaneous coronary intervention. Expert Rev Cardiovasc Ther 2007;5:81-9.

45. Sanmartin M, Baz JA, Claro R, et al. Comparison of drugeluting stents versus surgery for unprotected left main coronary artery disease. Am J Cardiol 2007;100:970-3.

46. Vaquerizo B, Lefevre T, Darremont O, et al. Unprotected left main stenting in the real world: two-year outcomes of the French left main taxus registry. Circulation 2009;119:2349-56.

47. Park DW, Seung KB, Kim YH, et al. Long-term safety and efficacy of stenting versus coronary artery bypass grafting for unprotected left main coronary artery disease: 5-year results from the MAIN-COMPARE (Revascularization for Unprotected Left Main Coronary Artery Stenosis: Comparison of Percutaneous Coronary Angioplasty Versus Surgical Revascularization) registry. J Am Coll Cardiol 2010;56:117-24.

48. Stone GW, Sabik JF, Serruys PW, et al. EverolimusEluting Stents or Bypass Surgery for Left Main Coronary Artery Disease. N Engl J Med 2016;375:2223-35.

49. Park SJ, Kim YH, Park DW, et al. Impact of intravascular ultrasound guidance on long-term mortality in stenting for unprotected left main coronary artery stenosis. Circ Cardiovasc Interv 2009;2:167-77.

50. de la Torre Hernandez JM, Baz Alonso JA, Gomez Hospital JA, et al. Clinical impact of intravascular ultrasound guidance in drug-eluting stent implantation for unprotected left main coronary disease: pooled analysis at the patient-level of 4 registries. JACC Cardiovasc Interv 2014;7:244-54.

51. Naganuma T, Chieffo A, Meliga E, et al. Long-term clinical outcomes after percutaneous coronary intervention for ostial/mid-shaft lesions versus distal bifurcation lesions in unprotected left main coronary artery: the DELTA Registry (drug-eluting stent for left main coronary artery disease): a multicenter registry evaluating percutaneous coronary intervention versus coronary artery bypass grafting for left main treatment. JACC Cardiovasc Interv 2013;6:1242-9.

52. Suter Y, Schoenenberger AW, Toggweiler S, et al. Intravascular ultrasound-based left main coronary artery assessment: comparison between pullback from left anterior descending and circumflex arteries. J Invasive Cardiol 2009;21:457-60.

53. Kang SJ, Ahn JM, Kim WJ, et al. Functional and morphological assessment of side branch after left main coronary artery bifurcation stenting with cross-over technique. Catheter Cardiovasc Interv 2014;83:545-52.

54. Kang SJ, Ahn JM, Song H, et al. Comprehensive intravascular ultrasound assessment of stent area and its impact on restenosis and adverse cardiac events in 403 patients with unprotected left main disease. Circ Cardiovasc Interv 2011;4:562-9.

55. Mitomo S, Jabbour RJ, Watanabe Y, et al. Comparison of mid-term clinical outcomes after treatment of ostial right coronary artery lesions with early and new generation drug-eluting stents: Insights from an international multicenter registry. Int J Cardiol 2018;254:53-8.

56. Sakakura K, Inohara T, Kohsaka S, et al. Incidence and Determinants of Complications in Rotational Atherectomy: Insights From the National Clinical Data (J-PCI Registry). Circ Cardiovasc Interv 2016;9:e004278.

57. Mavromatis K, Ghazzal Z, Veledar E, et al. Comparison of outcomes of percutaneous coronary intervention of ostial versus nonostial narrowing of the major epicardial coronary arteries. Am J Cardiol 2004;94:583-7.

58. Freeman M, Clark DJ, Andrianopoulos N, et al. Outcomes after percutaneous coronary intervention of ostial lesions in the era of drug-eluting stents. Catheter Cardiovasc Interv 2009;73:763-8.

59. Jokhi P, Curzen N. Percutaneous coronary intervention of ostial lesions. EuroIntervention 2009;5:511-4.

60. Costa MA, Angiolillo DJ, Tannenbaum M, et al. Impact of stent deployment procedural factors on long-term effectiveness and safety of sirolimus-eluting stents (final results of the multicenter prospective STLLR trial). Am J Cardiol 2008;101:1704-11.

61. Dishmon DA, Elhaddi A, Packard K, et al. High incidence of inaccurate stent placement in the treatment of coronary aorto-ostial disease. J Invasive Cardiol 2011;23:322-6.

62. Patel Y, Depta JP, Patel JS, et al. Impact of intravascular ultrasound on the long-term clinical outcomes in the treatment of coronary ostial lesions. Catheter Cardiovasc Interv 2016;87:232-40.

63. Fujii K, Carlier SG, Mintz GS, et al. Stent underexpansion and residual reference segment stenosis are related to stent thrombosis after sirolimus-eluting stent implantation: an intravascular ultrasound study. J Am Coll Cardiol 2005;45:995-8.

64. Fujino Y, Bezerra HG, Attizzani GF, et al. Frequencydomain optical coherence tomography assessment of unprotected left main coronary artery disease-a comparison with intravascular ultrasound. Catheter Cardiovasc Interv 2013;82:E173-83.

65. Oviedo C, Maehara A, Mintz GS, et al. Intravascular 
ultrasound classification of plaque distribution in left main coronary artery bifurcations: where is the plaque really located? Circ Cardiovasc Interv 2010;3:105-12.

66. Choi SY, Maehara A, Cristea E, et al. Usefulness of minimum stent cross sectional area as a predictor of angiographic restenosis after primary percutaneous coronary intervention in acute myocardial infarction (from the HORIZONS-AMI Trial IVUS substudy). Am J Cardiol 2012;109:455-60.

67. Park DW, Park SJ. Intravascular Ultrasound-Guided Percutaneous Coronary Intervention for Left Main Disease: Does Procedural Fine-Tuning Make a Relevant Clinical Benefit? Circ Cardiovasc Interv 2017;10:e005293.

68. Latib A, Colombo A. Bifurcation disease: what do we know, what should we do? JACC Cardiovasc Interv 2008;1:218-26.

69. Steigen TK, Maeng M, Wiseth R, et al. Randomized study on simple versus complex stenting of coronary artery bifurcation lesions: the Nordic bifurcation study. Circulation 2006;114:1955-61.

70. Colombo A, Bramucci E, Sacca S, et al. Randomized study of the crush technique versus provisional side-branch stenting in true coronary bifurcations: the CACTUS (Coronary Bifurcations: Application of the Crushing Technique Using Sirolimus-Eluting Stents) Study. Circulation 2009;119:71-8.

71. Maeng M, Holm NR, Erglis A, et al. Long-term results after simple versus complex stenting of coronary artery bifurcation lesions: Nordic Bifurcation Study 5-year follow-up results. J Am Coll Cardiol 2013;62:30-4.

72. Okabe T, Mintz GS, Buch AN, et al. Intravascular ultrasound parameters associated with stent thrombosis after drug-eluting stent deployment. Am J Cardiol 2007;100:615-20.

73. Routledge HC, Morice MC, Lefevre T, et al. 2-year outcome of patients treated for bifurcation coronary disease with provisional side branch T-stenting using drugeluting stents. JACC Cardiovasc Interv 2008;1:358-65.

74. Dangas GD, Caixeta A, Mehran R, et al. Frequency and predictors of stent thrombosis after percutaneous coronary intervention in acute myocardial infarction. Circulation 2011;123:1745-56.

75. Yakushiji T, Maehara A, Mintz GS, et al. An intravascular ultrasound comparison of left anterior descending artery/ first diagonal branch versus distal left main coronary artery bifurcation lesions. EuroIntervention 2013;8:1040-6.

76. Kim JS, Hong MK, Ko YG, et al. Impact of intravascular ultrasound guidance on long-term clinical outcomes in patients treated with drug-eluting stent for bifurcation lesions: data from a Korean multicenter bifurcation registry. Am Heart J 2011;161:180-7.

77. Choi SY, Witzenbichler B, Maehara A, et al. Intravascular ultrasound findings of early stent thrombosis after primary percutaneous intervention in acute myocardial infarction: a Harmonizing Outcomes with Revascularization and Stents in Acute Myocardial Infarction (HORIZONS-AMI) substudy. Circ Cardiovasc Interv 2011;4:239-47.

78. Katayama T, Kubo N, Takagi Y, et al. Relation of atherothrombosis burden and volume detected by intravascular ultrasound to angiographic no-reflow phenomenon during stent implantation in patients with acute myocardial infarction. Am J Cardiol 2006;97:301-4.

79. Raber L, Mintz GS, Koskinas KC, et al. Clinical use of intracoronary imaging. Part 1: guidance and optimization of coronary interventions. An expert consensus document of the European Association of Percutaneous Cardiovascular Interventions. EuroIntervention 2018;14:656-77.

80. Satler LF, Hoffmann R, Lansky A, et al. Carotid StentAssisted Angioplasty: Preliminary Technique, Angiography, and Intravascular Ultrasound Observations. J Invasive Cardiol 1996;8:23-30.

81. Brilakis ES, Grantham JA, Rinfret S, et al. A percutaneous treatment algorithm for crossing coronary chronic total occlusions. JACC Cardiovasc Interv 2012;5:367-79.

82. Mintzer J. Perspective from Clinical Research: Ethical Issues in Alzheimer's Disease Research. J Law Med Ethics 2018;46:699-703.

83. Maehara A, Mintz GS, Witzenbichler B, et al. Relationship Between Intravascular Ultrasound Guidance and Clinical Outcomes After Drug-Eluting Stents. Circ Cardiovasc Interv 2018;11:e006243.

84. Sharma SK, Bolduan RW, Patel MR, et al. Impact of calcification on percutaneous coronary intervention: MACE-Trial 1-year results. Catheter Cardiovasc Interv 2019;94:187-94.

85. Park Y, Park HS, Jang GL, et al. Intravascular ultrasound guided recanalization of stumpless chronic total occlusion. Int J Cardiol 2011;148:174-8.

86. Nissen SE, De Franco AC, Tuzcu EM, et al. Coronary intravascular ultrasound: diagnostic and interventional applications. Coron Artery Dis 1995;6:355-67.

87. Song L, Maehara A, Finn MT, et al. Intravascular Ultrasound Analysis of Intraplaque Versus Subintimal Tracking in Percutaneous Intervention for Coronary Chronic Total Occlusions and Association With Procedural 
Outcomes. JACC Cardiovasc Interv 2017;10:1011-21.

88. Tsujita K, Maehara A, Mintz GS, et al. Intravascular ultrasound comparison of the retrograde versus antegrade approach to percutaneous intervention for chronic total coronary occlusions. JACC Cardiovasc Interv 2009;2:846-54.

89. Muramatsu T, Tsukahara R, Ito Y. A novel intravascular ultrasound-guided percutaneous coronary angioplasty technique via the retrograde approach for chronic total occlusion. Cardiovasc Interv Ther 2011;26:45-51.

90. Dai J, Katoh O, Kyo E, et al. Approach for chronic total occlusion with intravascular ultrasound-guided reverse controlled antegrade and retrograde tracking technique: single center experience. J Interv Cardiol 2013;26:434-43.

91. Noguchi T, Miyazaki MS, Morii I, et al. Percutaneous transluminal coronary angioplasty of chronic total occlusions. Determinants of primary success and long-term clinical outcome. Catheter Cardiovasc Interv 2000;49:258-64.

92. Okamura A, Iwakura K, Iwamoto M, et al. Tip Detection Method Using the New IVUS Facilitates the 3-Dimensional Wiring Technique for CTO Intervention. JACC Cardiovasc Interv 2020;13:74-82.

93. Sotomi Y, Onuma Y, Suwannasom P, et al. Is quantitative coronary angiography reliable in assessing the lumen gain after treatment with the everolimus-eluting bioresorbable polylactide scaffold? EuroIntervention 2016;12:e998-e1008.

94. Shin DH, Hong SJ, Mintz GS, et al. Effects of Intravascular Ultrasound-Guided Versus AngiographyGuided New-Generation Drug-Eluting Stent Implantation: Meta-Analysis With Individual PatientLevel Data From 2,345 Randomized Patients. JACC Cardiovasc Interv 2016;9:2232-9.

95. Ben Ahmed H, Bouzouita K, Hamdi I, et al. Comparison of coronary calcifications detection by angiogram versus intravascular ultrasound. Tunis Med 2013;91:196-9.

Cite this article as: Malaiapan Y, Leung M, White AJ. The role of intravascular ultrasound in percutaneous coronary intervention of complex coronary lesions. Cardiovasc Diagn Ther 2020;10(5):1371-1388. doi: 10.21037/cdt-20-189
96. Mintz GS, Popma JJ, Pichard AD, et al. Patterns of calcification in coronary artery disease. A statistical analysis of intravascular ultrasound and coronary angiography in 1155 lesions. Circulation 1995;91:1959-65.

97. Voigtlander T, Rupprecht HJ, Scharhag J, et al. Intravascular ultrasound detected classification of coronary lesions as a predictor of dissections after balloon angioplasty. Int J Card Imaging 1996;12:179-83.

98. Hakim DA, Mintz GS, Sanidas E, et al. Serial gray scale intravascular ultrasound findings in late drug-eluting stent restenosis. Am J Cardiol 2013;111:695-9.

99. Henneke KH, Regar E, Konig A, et al. Impact of target lesion calcification on coronary stent expansion after rotational atherectomy. Am Heart J 1999;137:93-9.

100. Mosseri M, Satler LF, Pichard AD, et al. Impact of vessel calcification on outcomes after coronary stenting. Cardiovasc Revasc Med 2005;6:147-53.

101. Tuzcu EM, Berkalp B, De Franco AC, et al. The dilemma of diagnosing coronary calcification: angiography versus intravascular ultrasound. J Am Coll Cardiol 1996;27:832-8.

102. Tomey MI, Kini AS, Sharma SK. Current status of rotational atherectomy. JACC Cardiovasc Interv 2014;7:345-53.

103.Abdel-Wahab M, Richardt G, Joachim Buttner H, et al. High-speed rotational atherectomy before paclitaxeleluting stent implantation in complex calcified coronary lesions: the randomized ROTAXUS (Rotational Atherectomy Prior to Taxus Stent Treatment for Complex Native Coronary Artery Disease) trial. JACC Cardiovasc Interv 2013;6:10-9.

104. Kappetein AP, Serruys PW, Sabik JF, et al. Design and rationale for a randomised comparison of everolimuseluting stents and coronary artery bypass graft surgery in selected patients with left main coronary artery disease: the EXCEL trial. EuroIntervention 2016;12:861-72. 


\section{Supplementary}

Table S1 Quantitative IVUS measurements (105)

1. Lumen CSA = Area bounded by luminal border

2. Minimum luminal diameter $=$ Shortest diameter through center point of the lumen.

3. Maximum luminal diameter $=$ Longest diameter through center point of the lumen

4. Lumen eccentricity = Maximum luminal diameter - Minimum luminal diameter/Maximum luminal diameter

5. Lumen area stenosis $=$ Reference lumen CSA - Lesion lumen CSA/Reference lumen CSA

6. Plaque + Media (atheroma) cross section area $=$ EEM CSA - lumen CSA

7. \% Plaque area (atheroma /plaque burden) = Plaque + media CSA /EEM CSA

8. Stent CSA = Area bounded by coronary stent

9. Stent symmetry = Maximum stent diameter - Minimum stent diameter/Maximum stent diameter

10. Stent expansion $=$ Min. stent CSA compared with predefined reference segment CSA

\section{References}

105. Nissen SE, Yock P. Intravascular ultrasound: novel pathophysiological insights and current clinical applications. Circulation 2001;103:604-16. 